\title{
La crónica periodístico-literaria contemporánea en Chile
}

\author{
Patricia PoBlete AldAY \\ Universidad Academia de Humanismo Cristiano (UAHC, Santiago de Chile) \\ ppoblete@academia.cl
}

Recibido: 25 de julio de 2013

Aceptado: 4 de febrero de 2014

\begin{abstract}
Resumen
Durante el último decenio, la publicación de revistas y de antologías de crónicas periodístico-literarias, ha ido en notable aumento, lo que ha animado a no pocos críticos y estudiosos a hablar de un "nuevo boom de la literatura hispanoamericana". En ese contexto, este artículo realiza una mirada panorámica sobre el desarrollo de este género en Chile durante el presente siglo, identificando sus principales exponentes y sus características más relevantes. Junto a ello, se compara la actual crónica periodístico-literaria con la crónica históricamente precedente (fundacional, costumbrista y modernista), estableciendo sus continuidades y rupturas con miras a definir la especificidad de aquélla. Asimismo, se proponen criterios de análisis adecuados a esta 'nueva crónica', considerando como ejes básicos tanto su hibridez genérica y disciplinar, como su funcionalidad dentro de la sociedad contemporánea.
\end{abstract}

Palabras clave: Crónica contemporánea, Narrativa chilena, Periodismo, Literatura

\section{Journalism and literature: Contemporary chronicle in Chile}

\begin{abstract}
During the last decade, the publication of magazines and anthologies of literary-journalistic chronicles, has been on the sharp increase, which has encouraged quite a few critics to speak of a "new boom in Latin American literature." In this context, this article takes a panoramic view on the development of this genre in Chile during this century, identifying its main exponents and their relevant characteristics. Along with this, we compare the current journalistic-literary chronicle with the historical precedent chronicle (foundational, manners and modernist), establishing their continuities and ruptures in order to define the specificity of the contemporary chronicle. Finally, we propose criteria for adequate analysis of this 'new chronic', considered as basic and generic hybridity both their discipline, as their functionality within contemporary society.
\end{abstract}

Keywords: Contemporary chronicle, Chilean narrative, Journalism, Literature

\section{Referencia normalizada}

POBLETE ALDAY, Patricia (2014): "La crónica periodístico-literaria contemporánea en Chile". Estudios sobre el Mensaje Periodístico. Vol. 20, Núm. 2 (julio-diciembre), págs.: 1165-1176. Madrid, Servicio de Publicaciones de la Universidad Complutense.

Sumario: 1. Introducción. 2. Concepto y método. 3. Nueva crónica: academia y campo cultural. 4. Anacronía analítica. 5. Conclusiones. 6. Referencias bibliográficas.

\section{Introducción}

Desde la última década del siglo pasado, la crónica ha proliferado de forma notable en América Latina. Esta importancia creciente se ha visto reflejada en iniciativas como la fundación de instituciones y organismos destinados a promover el ejercicio periodístico más allá de su función informativa; en la creación de revistas que dan espacio

1 Parte de la investigación Fondecyt Iniciación $N^{\circ}$ 11110202, de la cual la autora es responsable. 
al periodismo narrativo de autor -como El Malpensante y SoHo (Colombia); Gatopardo y Letras Libres (México); Etiqueta Negra (Perú); Pie izquierdo (Bolivia); Orsái, Latido y Rolling Stone (Argentina), o Marcapasos (Venezuela)- y en la publicación de antologías a nivel continental, como Enviados especiales. Antología del nuevo periodismo latinoamericano (México, 2003); Lo mejor de Gatopardo (Colombia, 2005), Lo mejor del periodismo en América Latina (México, 2006), SoHo Crónicas (Colombia, 2008), Crónicas de otro planeta (México, 2009) o Domadores de historias. Conversaciones con grandes cronistas de América Latina (Santiago de Chile, 2011). La revista colombiana Cambio daba cuenta de este fenómeno en su edición del 5 de agosto de 2009, citando a Mario Jursich, director de la revista El Malpensante: "Si se hablara de un nuevo boom latinoamericano, no sería en el campo de la literatura sino de la crónica" ${ }^{2}$, afirmación que tres años más tarde rotularía la cinta roja de una antología de crónicas (Antología de crónica latinoamericana actual). Entre los factores citados en dicha nota para explicar este repunte, están la existencia de una larga tradición narrativa; la ausencia hoy de fenómenos literarios de proporciones, como fue el Boom; la aparición de revistas que usan la crónica como materia prima, y el impulso de las editoriales.

En Chile, este auge de la crónica se evidencia en hechos como la instauración del Premio Periodismo de Excelencia de la Universidad Alberto Hurtado, en 2003; y en la publicación de antologías como Dios es chileno (Planeta, 2008); Periodismo en el límite (Uqbar, 2008) o Historias de una mujer bomba y otras crónicas de América Latina (Uqbar, 2009). En su edición 197, la revista Capital le dedicó una nota a la emergencia de la crónica en Chile, donde se señala que "Algunos de los mejores libros publicados en el último tiempo no son novelas ni cuentos ni ensayos, sino crónicas ${ }^{3 "}$. Allí se destaca el trabajo de Alberto Fuguet, Álvaro Bisama, Rafael Gumucio, Francisco Mouat y Roberto Merino. En un artículo editorial del diario La Tercera, el crítico Matías Rivas pondera, igualmente, a Fuguet y Merino, pero agrega además a Pedro Lemebel como una pluma insoslayable en el actual panorama chileno de la crónica ${ }^{4}$.

\section{Concepto y método}

Para el abordaje de este fenómeno se seleccionaron crónicas recopiladas en libros, considerando el valor consagratorio (Chartier, 1987-1991) que dicho formato supone, y que funciona como índice, en sí mismo, de la notoriedad que esta forma textual ha alcanzado hoy en día. En este sentido, es significativo que en Chile, desde el año 2000 al 2012, se publicaron cerca de una cincuentena de antologías, individuales o colectivas, lo que constituye una cifra alta para un mercado editorial pequeño como el chi-

2 "Crónica periodística latinoamericana comienza a ganarle en prestigio al cuento y la novela". Consulta on line en <http://www.cambio.com.co/culturacambio/840/ARTICULOWEB-NOTA_INTERIOR_CAMBIO-5783627.html> [01/04/2011]

3 "Los nuevos cronistas", Capital 197, 26 enero 2007. Consulta on line en $<$ http://www.capital.cl/reportajes-y-entrevistas/los-nuevos-cronistas-singulares-e-insolentes-observado.html > [01/04/2011]

4 Matías Rivas: “Chile según sus cronistas” en La Tercera, Sección Opinión, 18/09/2009. Consulta on line en <http://latercera.com/contenido/661_183306_9.shtml > [01/04/2001] 
leno. En términos hispanoamericanos, además, resulta elocuente que sólo el año pasado se publicaron tres antologías: Mejor que ficción (Anagrama), Antología de crónica latinoamericana actual (Alfaguara) y Sam no es mi tío (Alfaguara EEUU). En estas últimas, en tanto, se incluyen textos de ocho cronistas chilenos, mientras que en el Diccionario abreviado de cronistas hispanoamericanos que cierra la antología de Carrión (la de Anagrama), de los 418 nombres listados, 20 corresponden a firmas chilenas $(5 \%)^{5}$.

El corpus analítico se focalizó en las obras de algunos de los cronistas más prolíficos y reconocidos hoy en día: Pedro Lemebel (1955), Roberto Merino (1961), Francisco Mouat (1962), Alberto Fuguet (1964), Juan Pablo Meneses (1969) y Rafael Gumucio (1970). Del análisis se desprenden una serie de características relevantes de lo que llamamos crónica contemporánea, y que la distinguen de sus manifestaciones precedentes:

- Primero: la creciente inclusión de las narrativas del Yo, lo que configura un momento autobiográfico (De Man, 1979) o espacio biográfico (Arfuch, 2002) dentro de estos textos, comprendidos como una serie de desplazamientos retóricos que tienden a lo biográfico sin constituirlo por completo. Esta particular forma de hibridez conjuga espacios y estrategias de enunciación; modalidades textuales canónicas y productos de la cultura de masas; subjetividades múltiples que concurren en los distintos momentos de producción y lectura del texto; y, sobre todo, la activación conjunta de horizontes de expectativas provenientes de distintos registros textuales. Con ello -más allá del narcisismo que por esta vía se puede, o no, traslucir- la crónica nos confronta con la movilidad de las fronteras entre lo público y lo privado, en cuyo vaivén se va constituyendo lo íntimo, que por lo mismo, ya no equivale -como en la época de la crónica modernista- a lo verdadero, ni tampoco a lo auténtico.

Si bien este aspecto es común a todos los cronistas estudiados, no se presenta de igual forma, ni con la misma fuerza, en la obra de cada uno de ellos. En un extremo podemos situar las crónicas de Alberto Fuguet, donde la presencia del Yo es central, operando no solo como criterio de orden y enunciación de aquello que refiere, sino como fuente de significación autorreferente. Para utilizar la distinción realizada por el argentino Martín Caparrós (2007): las crónicas de Fuguet no son simplemente textos escritos en primera persona, como modo de asentar la propia perspectiva y lugar de enunciación, sino que versan sobre la primera persona. Esto se revela en, al menos, dos aspectos principales. El primero es que los criterios de relevancia comunicativa que fundamentan la selección de los temas o hechos publicables se interpretan y aplican ya no en términos del interés grupal o periodístico, sino individual: es el cronista, y no el editor, quien juzga aquello que es importante, novedoso, cercano, impactante, susceptible de tener repercusiones, y lo hace basándose no tanto en la contingencia sino en su propio gusto o afinidad. Este matiz se aprecia fácilmente en los textos recopilados en Primera parte (2000). El segundo aspecto es la cerrazón sobre la propia interioridad del cronista (recuerdos, pensamientos, deseos, etc.), la que, junto a su bio-

5 El ranking lo encabezan, cuantitativamente, los argentinos (87), les siguen los mexicanos (70), los españoles (71), los colombianos (59) y los peruanos (39). 
grafía, más que prisma desde el cual se mira una realidad, se hace materia prima de la escritura. Este uso narrativo del Yo biográfico comienza a aparecer persistentemente en apuntes autistas (2007) y se lleva al extremo en Missing (una investigación) (2009), donde la subjetividad funde las figuras de autor y narrador, involucrando el propio desarrollo de la trama.

En el otro extremo, podríamos ubicar las crónicas de Roberto Merino y de Francisco Mouat, donde el Yo narrativo no es sino una presencia que facilita la emergencia del Otro. En el primero, el recurso a la propia biografia apunta a evocar un recuerdo colectivo, un 'espíritu de época' que pervive en las huellas de la ciudad a medida que ésta es recorrida. En sus crónicas urbanas -recopiladas en Santiago de memoria (1997), Horas perdidas en las calles de Santiago (2000), En busca del loro atrofiado (2005) y Todo Santiago (2012)- se actualiza el arquetipo del flanêur, donde la individualidad no es ya una biografía particular, sino la singularidad de una mirada. Así, el cronista se perfila como transductor, en el sentido dado al término por Doležel (1986). Esto es, realiza respecto a la ciudad la misma forma de transmisión dinámica de que son objeto las obras literarias, como intertextualidad, transferencia intercultural, recepción crítica, parodia, tradición, readaptaciones. Si la urbe es un gran conglomerado de signos y posibilidades de sentido, resulta evidente que en el ejercicio de parcelar ese universo, seleccionar algunos de sus aspectos y guiar nuestra atención hacia ellos, el cronista ya está operando como mediador entre la ciudad y nosotros (como habitantes y como lectores; de sus textos y del propio entorno). Pero, además, está inoculando su perspectiva de la ciudad en la mirada que habremos de dar luego sobre ella.

En el caso de las crónicas de Mouat, encontramos no tanto una activación de la memoria compartida, sino una reflexión sobre las particularidades del mismo mecanismo mnemnónico. En la exhibición de pasajes de la propia vida, y la reflexión que desde ellos se propicia, el Yo trasciende su singularidad para fundirse, en la lectura, con otros. Ejercicio performativo -autorial, a fin de cuentas- en este proceso la memoria es asumida como un arte poética y un imperativo moral, que alcanza altos grados de emocionalidad cuando se cierne sobre sus amigos y familiares fallecidos, en algunos textos de Tres viajes (2007), Algunos adioses (2010) y Calendario 2008-2011 (2011). Mouat oficia de canal y caja de resonancia para las historias mínimas, cotidianas, de personas desconocidas, construyendo una autoría compartida y cómplice. Quizás el texto donde esta particularidad exhibe mayor complejidad sea el que cierra Tres viajes, y que fue elaborado sobre la agenda de Dolores Ezcurra, amiga de Mouat. El texto primario, manuscrito, contiene de forma fragmentaria y caótica los síntomas del cáncer que habrían de acabar con la vida de Dolores; los tratamientos y exámenes a los que es sometida, las consultas médicas a las que debe asistir. El diario como tal se construye recién en la conjunción de esta escritura primaria y su lectura por parte de Mouat, quien interviene explicativamente las anotaciones (con cursivas) y documenta su propio proceso de lectura, que es, además, el proceso de asunción del duelo por su amiga ya fallecida. Porque el pasar en limpio su última agenda no equivale simplemente, como él indica, a "sentar[se] a tomar el té con ella y escucharla hablar por última vez" (113), sino que implica reconstruir, mediante el manuscrito, su derrotero hacia la muerte y acompañarla en esa agonía. 
- El segundo aspecto relevante de la crónica chilena contemporánea es el cultivo de una relación paródica con la tradición cronística y con su función de 'espejo de la realidad'. La hibridez genérica es utilizada en muchos casos para aludir a una modalidad textual degradada o en desuso, a la cual se vincula una ideología caduca. Siguiendo a Linda Hutcheon (1981), la parodia se constituiría aquí como metagénero que aúna distintos materiales textuales. Particularmente, las crónicas de Indias y la obra historiográfica son 'fagocitadas' por esta nueva crónica para desarmar, desde su propia materialidad, la cosmovisión dominante y reductora que aquéllas ayudaban a perpetuar. Esta operación de desmontaje se entiende aún más ampliamente en relación con el valor de denuncia y reivindicación que poseen las crónicas escritas desde los márgenes del canon (político, cultural, religioso), y que han dado a conocer, durante las últimas décadas, el lado $\mathrm{B}$ del discurso oficial (minorías sexuales y étnicas, pobreza extrema, segregación femenina, etc.)

Donde mejor se manifiesta este aspecto es en los textos de Rafael Gumucio y Pedro Lemebel. El primero de ellos revierte el derrotero de las crónicas de Indias para cuestionar una herencia colonial que se asume como una carga, que es tanto colectiva como individual. España, desde esta lectura, no es ya la madre patria, sino la "hermana solterona que uno compadece pero necesita, porque guarda en su casa deshabitada y oscura todas las reliquias de la familia" (2006:26). La desacralización de la historia, de sus hitos, y de sus propios relatos, anima también la escritura de Los platos rotos (2004) y Monstruos cardinales (2002), donde Gumucio mezcla diversos géneros y registros textuales para horadar la solemnidad del discurso historiográfico, así como su pretensión de veracidad y objetividad. En este punto, el recurso a la ficcionalización resulta relevante:

¿Para eso viajé tanto -pensó-, para encontrarme desnudo como al principio? Y sintió como una burla el canto de los pájaros, la tierra que hay que trabajar, la lluvia que cae cuando quiere. A la orilla del río Aconcagua, Diego de Almagro recordó con nostalgia fatal el oro que había dejado en el Cuzco, y la ciudad de piedra haciendo equilibrio entre la bruma y la selva. Y tuvo miedo de que este Chile no fuese un territorio sino el fin de su sueño de borracho. (Gumucio, 2004: 20)

Al erigirse como contratexto de aquellos escritos históricos, los textos de Gumucio problematizan en su parodia, las relaciones y fronteras canónicas que se han establecido desde entonces entre historia y literatura, verdad y ficción, objetividad y subjetividad, autor y narrador. Esto es: corroen en primera instancia la voluntad de representación y el delirio de objetividad, revelando que toda historia (con y sin mayúsculas) no es sino una gramática.

La farsa que denuncia Lemebel en sus crónicas, en cambio, no es de carácter epistemológico sino eminentemente político, y apunta a develar parcelas de realidad invisibilizadas por el poder y su lógica comunicacional. Sus crónicas, como ha sido vastamente estudiado ${ }^{6}$, cruzan la experiencia de una triple marginalidad: la de las mi-

${ }^{6}$ Este aspecto de la obra de Lemebel se encuentra vastamente desarrollada en la compilación crítica Desdén al infortunio (Fernando Blanco y Juan Poblete eds. Santiago: Cuarto Propio, 2010) 
norías sexuales, la de la pobreza y la de las culturas originarias, por lo que se asientan fuertemente en la función testimonial, activando un código de recepción veridictivo (Ochando, 2008), que demanda del lector no sólo la aceptación de lo narrado en tanto realidad, sino además una toma de partido ideológico ante ella.

- El tercer punto relevante en la crónica chilena contemporánea está dado por la explotación de la ambigüedad literaria-periodística como una estrategia narrativa de doble valor, simbólico y económico. A diferencia de los cronistas modernistas, desgarrados entre la ética poética y el imperativo de claridad informativa que personificaba el editor, los cronistas actuales se sirven con soltura y sin angustia del repertorio temático y narrativo abierto desde ambas disciplinas. La ostentación del uso de los recursos propiamente literarios ya no es una debilidad textual, sino un valor agregado que incrementa el precio-mercado de la pieza cronística, y al revés, la actualidad abre un vasto campo temático en el cual el cronista puede, desde incidir políticamente en la realidad, hasta realizar simples ejercicios de estilo. La conciencia de esta condición de posibilidad, antes que de limitación, se traduce en la frecuencia con la que la crónica se vuelve sobre sí misma, tematizando su propio proceso de gestación y elaboración. El texto "El trauma de escribir", de Roberto Merino, condensa de manera elocuente la recurrencia de este motivo:

"Aun en una crónica como ésta, las dudas pueden llegar a ser torturantes, sobre todo por un problema de pertinencia: ¿molestaré al lector esta semana otra vez con mis asuntos personales, con mis odiosidades, con mi humor acre, con mis anécdotas de dudosa catadura?, ¿repetiré una vez más la sobreexpuesta palabra 'yo'? [...] "una rara cualidad de las crónicas -y de la literatura en general- es su coherencia aparente, la fluidez verbal que impide notar los obstáculos que neurotizaron al firmante y los largos momentos -a veces una tarde entera- que dejó pasar entre un párrafo y otro" (Merino, 2005: 97-98)

El síndrome de la página en blanco aparece en las crónicas de casi todos los autores analizados; en cambio, el valor comercial de sus piezas es abordado de forma directa y explícita por sólo uno de ellos: Juan Pablo Meneses, para quien una crónica es, entre otras cosas, un producto vendible al mejor postor:

"Les advierto [a los periodistas recién egresados] que no solo van a tener que escribir y viajar (los dos grandes amores del periodista), sino que deberán aprender a buscar temas, producir historias, vender artículos, financiar reportajes, negociar una buena paga, y además cobrarla. Y para cobrarla no solo deberán tener paciencia (algunos, especialmente en Latinoamérica, llegan a tardar más de un año en pagarte), sino que también deben tener una adecuada cuenta de banco, facturas internacionales (el freelance suele trabajar para varios países) y hasta un código Swift para los reembolsos en otras monedas". (Meneses, 2009: 38)

Y hoy por hoy, considerando el auge arriba descrito, el mercado editorial parece estar dispuesto a pagar.

\section{Nueva crónica: academia y campo cultural}

La llamada posmodernidad parece abonar -en la más amplia acepción del término- la hibridez constitutiva de la crónica. Sin embargo, acaso por la cantidad de elementos que la constituyen y la multiplicidad de las relaciones que dichos elementos establecen entre sí, esta hibridez ha sido poco y mal estudiada dentro del circuito académico. 
Más allá de las taxonomías propuestas para intentar definir qué es la crónica periodístico-literaria, o literario-periodística (Egan, 2004; Villoro, 2006), los estudios no han reflexionado detenidamente sobre las especificidades de esa hibridez, ni la han relacionado explicativamente con variables de gran relevancia, como son la posición autorial/narrativa, o los usos/finalidades del texto crónica. Tal carencia se advierte en los reclamos de dos reconocidos estudiosos del tema:

"Los estudios sobre las relaciones entre periodismo y literatura han sido dispersos y ocasionales, impresionistas y, en general, carentes de rigor [...] de un lado, historiadores y críticos literarios no han creído necesario ocuparse del periodismo, ni mucho menos de las conexiones que éste guarda con la literatura; de otro, los estudiosos del periodismo y la comunicación, quizás a causa de la adolescencia de las disciplinas que cultivan, han menospreciado o simplemente soslayado la cuestión" (Chillón,1999: 395)

La crónica es un producto híbrido, un producto marginado y marginal, que no suele ser tomado en serio ni por la institución literaria ni por la periodística, en ambos casos por la misma razón: el hecho de no estar definitivamente dentro de ninguna de ellas. Los elementos que una reconoce como propios y la otra como ajenos sólo han servido para que se la descarte, ignore o desprecie precisamente por lo que tiene de diferente. (Rotker, 2005: 225)

Creemos que la principal razón de esta omisión no estriba en una falta de interés por este modo textual, sino en la inadecuación de las herramientas crítico-analíticas que hemos heredado de una academia cerrada sobre los géneros canónicos, y excluyente respecto de los productos que surgen desde, o en conjunción con, la lógica mediática y masiva. Comprensiblemente, ello ha generado hondas imprecisiones a la hora de abordar las relaciones textuales entre literatura y periodismo, y que se ilustran en ejemplos como el siguiente, donde la misma vaguedad de la definición se vuelve elocuente: "periodismo y literatura fluyen e interactúan de muchas maneras y en cada caso (cada medio, cada autor u obra) sus códigos se articulan produciendo distintos efectos, y éstos cambian según el momento, el lugar, el lector" (Martínez y Delucchi, 2008: 49).

\section{Anacronía analítica}

Son también tres los puntos donde urge subsanar esta anacronía analítica. El primero es la indiferenciación del rótulo 'crónica', que se utiliza indistintamente para referirse a -y, esto es lo más grave: también para criticar- textos que no son homologables entre sí. Y es que en la crónica contemporánea se distinguen dos 'vertientes', que aunque se valen de estrategias narrativas similares o idénticas, obedecen a prácticas y finalidades distintas: de un lado, la 'literaria', comprendida como el acercamiento de literatos a los géneros más periodísticos; y del otro, la 'periodística', donde el sujeto periodístico, desde su rol de reportero, organiza y estructura su texto conjugando principios narrativo-literarios con los informativo-interpretativos, sin que por ello la función periodística deje de regir la economía del escrito. Precisamos que no se trata de delimitar estrategias textuales ni de proponer subcategorías genéricas; esfuerzo improcedente, por lo demás, si consideramos que la crónica es, desde su nacimiento, una 
forma escritural híbrida, proteica y transdisciplinar. Por ello, en vez de referir dos tipos de crónicas distintas, creemos más pertinente hablar de dos desplazamientos hacia su práctica, guiados por lógicas disímiles y no siempre confluentes.

Una prueba consistente de la indiferenciación crítica entre ambos desplazamientos cronísticos la constituye el hecho de que estos textos aparecen 'juntos y revueltos' en las tres antologías ya mencionadas. Para precisar el caso chileno, de los ocho cronistas incluidos en ellas, la mitad cabe dentro de la primera vertiente (Pedro Lemebel, Alejandro Zambra, Andrea Jeftanovic y Carola Saavedra), y la otra mitad, en la segunda (Juan Pablo Meneses, Cristián Alarcón, Cristóbal Peña y Alberto Fuguet). Sus textos, asimismo, se estructuran desde una matriz narrativo-ensayística (en el caso del primer grupo) y desde una informativo-interpretativa (en el caso del segundo grupo), sin que se observen marcas editoriales (capítulos, apartados, etc.) que señalen tal diferencia.

El segundo punto conflictivo identificado elimina u omite buena parte del corpus cronístico actual. Esto porque -salvo excepciones, como en todo- para la crítica académica, la 'crónica' equivale únicamente al texto de no ficción escrito por literatos, y se ignora aquél texto cronístico que se elabora desde la práctica periodística, aunque combinando sus criterios con una lógica compositiva que es innegablemente literaria. Esto porque, desde la rígida clasificación genérica de la que aún no logramos desembarazarnos del todo, la crónica narrativo-periodística, al no surgir desde la cantera literaria, carecería de valor estético, o éste sería insuficiente para reconocerle rango de literatura. Para volver al ejemplo que nos proporciona el mercado editorial chileno, de los casi cincuenta libros de crónicas publicados en la última década, la gran mayoría pertenece a escritores-literatos, que son llamados por los medios de comunicación escritos a publicar crónicas precisamente en virtud de su notoriedad en tanto autores de géneros más canónicos, como la novela, el cuento o la poesía. En consecuencia, las crónicas resultantes se acercan a la columna de opinión, a la grueguería, al ensayo, a la crítica o a la reseña literaria, pero son llamadas "crónicas" por la indiferenciación antes aludida, y son validadas en tanto material académico en virtud de la filiación literaria de su autor. Porque lo que prima en estos textos es la forma en la cual el autor ve el mundo (externo y/o interno) y su particular forma de interpretación (Martin Vivaldi, 1973); esto es, el Yo que firma vale más que aquello que refiere.

En cambio, los libros de crónicas escritos por periodistas, o guiados por un afán informativo-interpretativo, son referidos como reportajes en profundidad, y apuntan esencialmente a develar escándalos o sucesos de relevancia noticiosa ${ }^{7}$. La perspectiva autorial que se reconoce aquí es extratextual, permaneciendo en el ámbito del reporteo: el Yo ya no vale tanto como una mirada específica, sino sobre todo como una estrategia de consecución de la información. Consecuentemente, estos textos son

7 Por ejemplo: Operación Siglo XX, de Patricia Verdugo (Cesoc, 1996) y Los pistoleros (Debate, 2007), de Cristóbal Peña, ambos sobre el fallido atentado a Pinochet por el FPMR en 1986; La misión era matar (Lom, 2000), de Jorge Escalante, sobre el caso Caravana de la Muerte; Sexo y poder. El extraño destape chileno (Planeta, 2004), de Juan Pablo Meneses, que aborda ciertos casos de corrupción y abusos sexuales en altas esferas del país; o La caída (Francisco Sagredo, 2011), sobre el 'tráfico de influencias' dentro del negocio del fútbol. 
académicamente validados sólo en el ámbito de las ciencias de la comunicación. No deja de ser relevante, en este punto, que de los seis cronistas que integran el corpus referido para esta investigación -corpus que seleccionado, como se dijo, en virtud del reconocimiento público de los autores- cinco de ellos ejercen la labor cronística desde la función literaria, lo que da una clara idea de esta suerte de ignorancia o menosprecio general hacia el componente estético de la crónica narrativo-periodística.

El tercer punto, por último, apunta a la persistencia de una imagen obsoleta del cronista, al que en gran parte se sigue identificando su antecedente modernista. Las particularidades de la crónica contemporánea antes descritas -y que deben ser entendidas, por supuesto, en directa relación con el contexto sociocultural en el que surgen y con el cual dialogan- hablan por sí solas de la emergencia de una nueva figura del cronista, que ya no es ni el flâneur del XIX ni el reportero impertinente del new journalism, sino que combina ambos arquetipos desde una creciente autoconciencia autorial. El cronista actual reivindica el valor estético de sus textos, y de sí mismo en tanto escritor dotado de una mirada con prisma literario, renegando con ello de estigma de simple reproductor de hechos que le ha sido achacado, en gran parte, desde los cenáculos culturales. Con ello se sitúa como actor relevante dentro del campo cultural (Bourdieu, 1992), siendo sus estrategias de legitimación más visibles:

1) La creación de instituciones destinadas a promover el ejercicio confluente del periodismo y la literatura, como la Fundación Nuevo Periodismo Iberoamericano, creada por Gabriel García Márquez en 1994, o la Fundación Tomás Eloy Martínez, creada por sus herederos en Buenos Aires, durante el año 2010 y siguiendo los deseos de aquél. Mientras la primera declara como su misión general "estimular las vocaciones, la ética y la buena narración en el periodismo", la segunda, junto con preservar la obra del escritor argentino busca "promover la literatura y el periodismo latinoamericanos". El hecho de que ambas instituciones hayan sido impulsadas por figuras reconocidas opera, por supuesto, como un espaldarazo que ayuda a validar, a ojos del gran público y de la crítica renuente, no sólo al texto cronístico, sino también a sus nuevos autores. Similar función cumplen los prólogos y "cintas rojas" que acompañan a los libros de crónicas, con frases elogiosas que valen más por su firma que por los halagos que contienen. En esta lógica, Juan Villoro "apadrina" a Meneses; Jon Lee Anderson "avala" a Villanueva Chang; Martín Caparrós "presenta" a Cristián Alarcón; siendo esos "actos de fe" parte de la alquimia simbólica (Bourdieu, 1992) que contribuye a crear el valor de la obra.

2) La circulación de programas, decálogos, prólogos y textos 'fundacionales'y medianamente prescriptivos, que delimitan el corpus, y la práctica, de lo que los mismos periodistas consideran crónica narrativa. Es importante señalar que estos textos son escritos desde la misma praxis cronística, fuera de los márgenes de la academia; por ejemplo: "Reglas quebrantables para periodistas literarios", de Mark Krammer; "La crónica, una mirada extrema", de Martín Caparrós; "Mutación de la crónica", de Pablo Mancini; todos textos publicados en revistas periodístico-narrativas: El Malpensante

8 Ver $<$ www.fnpi.org $>$. Consulta on line 28/03/2011.

9 Ver $<$ http://fundaciontem.org/lafundacion/> Consulta on line 06/10/2012 
(agosto-septiembre 2001), Crónica (15/09/2007), y Amphibia (octubre 2012), respectivamente.

3) La instauración de premios, que operan como instancias auto-consagratorias. En 2001, la FNPI lanzó la primera edición del Premio Cemex-FNPI para trabajos cronísticos de este tipo, el que se mantuvo hasta 2010 y fue recientemente reemplazado por el premio de periodismo Gabriel García Márquez. La editorial Planeta otorga desde 2006 el Premio de Crónica Planeta/Seix Barral en conjunto con la Fundación Nuevo Periodismo Iberoamericano. En 2010, la Universidad de Guadalajara y la Escuela de Periodismo Portátil, del chileno Juan Pablo Meneses, lanzaron el Premio Las Nuevas Plumas, destinado a cronistas jóvenes. Y no es menor el reciente reconocimiento al colombiano Alberto Salcedo Ramos, galardonado el pasado mes de abril con el prestigioso premio Ortega y Gasset.

\section{Conclusiones}

Situados en una época donde la literatura pierde especificidad y autonomía (Ludmer, 2010), donde se diluyen las fronteras genéricas, y los textos transitan con soltura entre lo culto-literario y lo mediático-masivo, se hace imprescindible revisar, antes que todo, las categorías analíticas y el aparataje teórico con el que abordamos críticamente los textos. Ello implica problematizar también el criterio de 'lo literario' en su sentido privativo (esto es, como la elaboración de mundos ficticios mediante un lenguaje autorreferente) y en su delimitación genérica; asumiendo en consecuencia, que la escrituras que cruzan modos textuales y lógicas diversas -como hace la crónica contemporánea, escrita desde el periodismo- deben ser admitidas dentro del corpus literario, a riesgo de desactualizar nuestro propio campo de estudio. Desde ahí, es factible realizar lo que hoy nos cuesta tanto: reconocer el valor estético de la crónica narrativa en conjunción con, y no en oposición a, su valor informativo-interpretativo, lo que -a la luz de lo antes dicho- constituye la piedra angular de cualquier aproximación crítica a la crónica narrativa actual.

Si en su imprescindible estudio sobre la crónica, Julio Ramos (1989) se situó en una época en la cual se disolvían los códigos que hasta entonces habían garantizado el lugar paradigmático de la escritura en el tejido de la comunicación social, tras el asentamiento del sistema mediático de masas, hoy en día asistimos a su expansión y ramificación en distintos formatos y vías. Este nuevo contexto debiera hacernos reflexionar sobre la advertencia que hacía Roberto González Echevarría en el prólogo a la nueva edición de Mito y archivo (2011), en el sentido de que el creciente influjo de los medios de comunicación y sus códigos -desde donde también, agregamos, cabe comprender la crónica contemporánea- bien podrían estar configurando hoy lo que, a futuro, acaso podríamos identificar como un nuevo relato maestro para la literatura latinoamericana.

\section{Referencias bibliográficas}

ARFUCH, Leonor (2002): El espacio biográfico. Dilemas de la subjetividad contemporánea. Buenos aires, FCE. 
BOURDIEU, Pierre (1992): Las reglas del arte. Génesis y estructura del campo literario. Barcelona, Anagrama.

CAPARRÓS, Martín (2007): "Por la crónica", en JARAMILLO AGUDELO, Darío (ed.): Antología de crónica latinoamericana actual. Madrid, Alfaguara, pp. 607612.

CHARTIER, Roger (1987-1991): Libros, lecturas y lectores en la edad Moderna. Madrid, Alianza.

CHILLÓN, Albert (1999): Literatura y periodismo. Una tradición de relaciones promiscuas. Barcelona, Universitat Autònoma de Barcelona / Universitat Jaume I / Universitat de Valencia.

DE MAN, Paul [1979]: "La autobiografía como desfiguración", en LOUREIRO, Ángel (coord.): La autobiografía y sus problemas teóricos. Barcelona, Anthropos, pp. 113-118.

DOLEŽEL, Lubomir (1986): "Semiótica de la comunicación literaria", en MAESTRO, Jesús G. (comp.): Nuevas perspectivas en semiología literaria. Madrid, Arcolibros, pp. 173-218.

EGAN, Linda (2004): Carlos Monsiváis. Cultura y crónica en el México contemporáneo. México, FCE.

FUGUET, Alberto (2009): Missing (una investigación). Santiago, Alfaguara.

FUGUET, Alberto (2007): Apuntes autistas. Santiago, Aguilar.

FUGUET, Alberto (2000): Primera parte. Santiago, Punto de Lectura.

GONZÁLEZ ECHEVARRÍA, Roberto (1990): Mito y archivo. Una teoría de la narrativa latinoamericana. México, FCE.

GUMUCIO, Rafael (2006): Páginas coloniales. Buenos Aires, Mondadori.

GUMUCIO, Rafael (2004): Los platos rotos. Historia personal de Chile. Santiago, Sudamericana.

GUMUCIO, Rafael (1999): Memorias prematuras. Santiago, Random House.

GUMUCIO, Rafael (1999): Monstruos cardinales. Santiago, Sudamericana.

HUTCHEON, Linda (1981): "Ironía, sátira, parodia. Una aproximación pragmática a la ironía", en De la ironía a lo grotesco (en algunos textos literarios hispanoamericanos). VV.AA., México, UAM, pp. 173-193.

LUDMER, Josefina (2010): Aqui América Latina. Una especulación. Buenos Aires, Eterna Cadencia.

MARTÍNEZ, Silvia y DELUCCHI, Eduardo (2008): ¿Cómo se vinculan el periodismo y la literatura? Buenos Aires, Biblos.

MENESES, Juan Pablo (2009): "Escuela móvil de periodismo portátil”, en revista Isla Flotante, I, 1, UAHC, Santiago de Chile, Invierno, pp. 33-40.

MERINO, Roberto (2012): Todo Santiago. Santiago, Hueders. 
MERINO, Roberto (2005): En busca del loro atrofiado. Santiago, JC Sáez Editor.

MERINO, Roberto (2000): Horas perdidas en las calles de Santiago. Santiago de Chile, Sudamericana.

MERINO, Roberto (1997): Santiago de memoria. Santiago, Planeta.

MOUAT, Francisco (2011): Calendario 2008-2011. Santiago, Lolita Editores.

MOUAT, Francisco (2010): Algunos adioses. Santiago, Lolita Editores.

MOUAT, Francisco (2007): Tres viajes. Santiago, Random House Mondadori.

OCHANDO, Carmen (2008): La memoria en el espejo. Aproximación a la escritura testimonial. Barcelona, Anthropos.

RAMOS, Julio (1989): Desencuentros de la Modernidad en América Latina: literatura y politica en el siglo XIX. México, FCE.

ROTKER, Susana (2005): La invención de la crónica. México, FCE/Fundación para un Nuevo Periodismo Iberoamericano.

VILLORO, Juan (2006): "La crónica, ornitorrinco de la prosa”, en JARAMILLO AGUDELO, Darío (ed.): Antología de crónica latinoamericana actual. Madrid, Alfaguara, pp. 577-582. 